\title{
Apolipoprotein A-I Mimetic 4F Peptide Generates Amyloid Cytotoxins by Forming Hetero-oligomers with $\beta$-amyloid
}

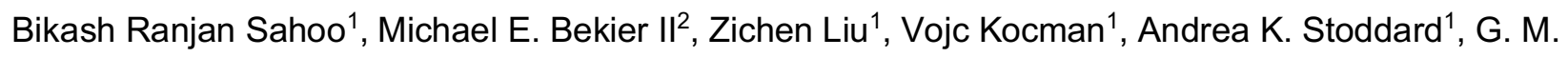
Anantharamaiah ${ }^{3}$, James Nowick ${ }^{4}$, Carol A. Fierke ${ }^{5}$, Yanzhuang Wang ${ }^{2}$, Ayyalusamy Ramamoorthy ${ }^{* 1}$

${ }^{1}$ Biophysics and Department of Chemistry, Biomedical Engineering, Macromolecular Science and Engineering, University of Michigan, Ann Arbor, MI 48109-1055, USA

${ }^{2}$ Department of Molecular, Cellular and Developmental Biology, University of Michigan, Ann Arbor, MI 48109-1055, USA

${ }^{3}$ Department of Medicine, University of Alabama at Birmingham Medical Center, Birmingham, Alabama, 35294, USA

${ }^{4}$ Department of Chemistry, University of California-Irvine, Irvine, CA 92697-2025, USA

${ }^{5}$ Department of Chemistry, University of Texas A\&M, College Station, TX 77843-3255, USA 


\section{Abstract}

Apolipoproteins are involved in pathological conditions of Alzheimer's disease (AD), truncated apolipoprotein fragments and $\beta$-amyloid $(A \beta)$ peptides coexist as neurotoxic heteromers within the plaques. Therefore, it is important to investigate these complexes at the molecular level to better understand their properties and roles in the pathology of AD. Here, we present a mechanistic insight into such heteromerization using a structurally homologue apolipoprotein fragment of apoA-I (4F) complexed with $A \beta(M 1-42)$ and characterize their toxicity. The $4 \mathrm{~F}$ peptide slows down the aggregation kinetics of $A \beta(M 1-42)$ by constraining its structural plasticity. NMR and $C D$ experiments identified $4 \mathrm{~F}-\mathrm{A} \beta(\mathrm{M} 1-42)$ heteromers as being comprised of unstructured $A \beta(M 1-42)$ and helical 4F. A uniform $\approx 2$-fold reduction in $A \beta 42{ }^{15} \mathrm{~N} /{ }^{1} \mathrm{H}$ NMR signal intensities with no observable chemical shift perturbation indicated the formation of a large complex, which was further confirmed by diffusion NMR experiments. Microsecond scale atomistic molecular dynamics simulations showed that $4 \mathrm{~F}$ interaction with $\mathrm{A} \beta(\mathrm{M} 1-42)$ is electrostatically driven and induces unfolding of $A \beta(M 1-42)$. Neurotoxicity profiling of $A \beta(M 1-42)$ complexed with $4 F$ confirms a significant reduction in cell-viability and neurite growth. The molecular architecture of heteromerization between $4 \mathrm{~F}$ and $\mathrm{A} \beta(\mathrm{M} 1-42)$ discovered in this study provides evidence towards our understanding of the role of apolipoproteins or their truncated fragments in exacerbating AD pathology.

Keywords: amyloid $\beta$; Alzheimer's disease; Apolipoproteins, Amyloid oligomers, Protein misfolding and aggregation 


\section{Introduction}

Aberrant protein folding and aggregation are associated with a variety of neurodegenerative disorders including Alzheimer's disease (AD), Parkinson's disease and prion disease $^{1-3}$ and non-neuropathic disease like type-2 diabetes (T2D). The progression of these diseases is linked with the accumulation of insoluble fibrillary aggregates (also called amyloidplaques) from water-soluble protein monomers such as $\beta$-amyloid $(A \beta)$ cleaved from the amyloidprecursor protein (APP), which has been intensely investigated to support the amyloid hypothesis cascade. Although the molecular basis of amyloid-deposition is not fully understood, several studies have identified the formation of water-soluble $A \beta$ peptide oligomers from monomers prior to the formation of metastable amyloid fibers. Interestingly, an increasing amount of evidence has recently shown the association of these cytotoxic oligomers (also called cytotoxins) to human neurons or pancreatic $\beta$-cells. ${ }^{4}$ The presence of oligomers surrounding amyloid plaques has also been identified as a distinguishable morphological hallmark in patients with dementia as compared to healthy people with a similar plaque morphology but not dementia. ${ }^{5}$ Although the characterization of such oligomers (namely amylospheroids, protofibrils, paranuclei, globulomers etc.) remains challenging due to their morphological heterogeneity, their relatively high neurotoxicity as compared to monomers or amyloid fibers directs researchers to target these species for therapeutic developments.

While there is significant interest in fully characterizing $A \beta$ oligomers due to their roles in the pathogenesis of $A D,{ }^{6}$ several studies have shown the co-occurrence of other cellular cofactors including proteins ${ }^{7}$ such as apolipoprotein fragments in the formation of hetero-oligomers. ${ }^{8}$ The 35-kDa apolipoprotein-E (apoE) and proteolytically cleaved apoE fragments are associated with $A \beta$ and have recently been identified from the brain of an $A D$ patient. ${ }^{8-10}$ Accumulation of apoE$A \beta$ complex has been identified in $A D$ cortical synapses from human brain specimens. ${ }^{11}$ apoE is 
involved in the modulation of $A \beta$ metabolism, aggregation and clearance, ${ }^{12,13}$ a recent in vitro study showed that apoE3, apoE4 and different fragments of apoE4 derived from $\mathrm{N}$ - or C-terminus substantially delay $A \beta(1-42)$ aggregation kinetics. ${ }^{14}$ Other neuroprotective apolipoproteins such as apoA-I and apo-J have also been observed in AD brains and heteromerization of apoA-I/A has been suggested to play a neuroprotective role. ${ }^{15-19}$ provide strong evidence that truncated apolipoprotein fragments and their interactions with $A \beta$ play critical roles in AD progression.

Several approaches have been used to directly modulate amyloid aggregation and oligomerization pathways as possible $A D$ treatments including binding of small-molecule inhibitors, peptides, polymers, cellular co-factors like ions, cell-membrane, enzymes, and chaperones. ${ }^{20-24}$ Other indirect approaches such as enhancing $A \beta$ clearance pathways to control $A D$ progression have also been reported..$^{25}$ One such approach is the enhancement of apoE secretion that promotes $A \beta$ cellular trafficking and degradation by using apolipoprotein mimetic peptides. ${ }^{26}$ Nevertheless, apoE antagonist has been designed to block the interaction between APP and apoE that enhances $A \beta$ production. ${ }^{27}$ Recently, an apoA-I mimetic peptide (4F) has been shown to directly inhibit $A \beta(1-40)$ aggregation ${ }^{28}$ and was also identified to upregulate apoE secretion to promote $A \beta$ 's clearance. ${ }^{26}$ Moreover, the $4 \mathrm{~F}$ peptide has also been shown to have an excellent medical application for several other human diseases. ${ }^{29-32}$ These findings urge a need for deeper understanding of their biomedical application in amyloidosis especially in $A D$ progression.

Several studies have used short peptide inhibitors/modulators for AD treatment; however, none of them have been successful in clinical trials indicating our poor understanding of the molecular basis of the disease progression. Furthermore, blocking $A \beta$ aggregation may even increase the risk of generating cytotoxic $A \beta$ oligomers or other intermediates. ${ }^{33-35}$ Alternative approaches such as promotion of quick fibrillation of $A \beta$ by chemical modulators to suppress the generation of cytotoxic intermediates have recently been reported ${ }^{36-38}$. Together with the recent discovery of apoE-fragment/A $\beta$ heteromer in $A D$ brains, ${ }^{8}$ this raised a concern that the $4 \mathrm{~F}$ 
inhibition of $A \beta$ may possibly generate cytotoxic $A \beta$ species. ${ }^{28}$ Similarly, a previous in vivo study showed the apoE-A $\beta$ complex reduces the level of soluble species and increases the $A \beta$ oligomer levels that are known to be neurotoxic. ${ }^{39}$ The binding of apoE to $A \beta$ oligomers at substoichiometric and to fibers at high concentration has also been demonstrated in vitro indicating their crucial involvement during amyloid fibrillation. ${ }^{40}$ Therefore, there is an urgent need to investigate the mechanism of heteromerization between apolipoprotein fragments and $A \beta$ in correlation with their toxicity and disease progression. The insights gained from such mechanisms could enable the design of better therapeutic strategies to detoxify these cytotoxins.

Herein, we investigated the interaction between the apolipoprotein peptide fragment $4 \mathrm{~F}$ and $A \beta(M 1-42)$. Our results reveal a substantial binding between $4 F$ and $A \beta(M 1-42)$ as recently observed for $A \beta_{1-40 .} A$ structural model showing the formation of hetero-oligomers is developed using a combination of biophysical methods including NMR and multi-microseconds all-atom and coarse-grained molecular dynamics (MD) simulations. Pathological phenotype characterization of the isolated $4 \mathrm{~F}-\mathrm{A} \beta(\mathrm{M} 1-42)$ hetero-oligomer shows an elevated cellular toxicity as compared to $\mathrm{A} \beta(\mathrm{M} 1-42)$ aggregates.

\section{Results and Discussion}

\section{F peptide retards $A \beta(M 1-42)$ fibrillation}

To investigate the involvement of apolipoproteins and their fragments in the pathology of $A D$ and $T 2 D$, we selected apoA-I mimetic 4F peptide that share structural homologs with Cterminal apoE fragments and apoA-I..$^{8,41}$ The effect of $4 \mathrm{~F}$ peptide on the aggregation kinetics of $A \beta(M 1-42)$ was first monitored using thioflavin-T (ThT) based fluorescence assay. In the absence of $4 \mathrm{~F}$ peptide, $A \beta(\mathrm{M} 1-42)(5 \mu \mathrm{M})$ showed a very short lag-time (<2 hour) of aggregation (Fig. 1a). On the other hand, a significant difference in $A \beta(M 1-42)$ aggregation kinetics was observed in the presence of equimolar $4 F$. The lag-time of $A \beta(M 1-42)$ fibrillation was increased by a factor of $\approx 24$ to keep the amount of fibril nearly the same as observed in the absence of 4F (Fig. 1a). With further increase in $4 \mathrm{~F}$ concentration (i.e. at 25 or $50 \mu \mathrm{M}$ ), a substantial fluorescence quenching 


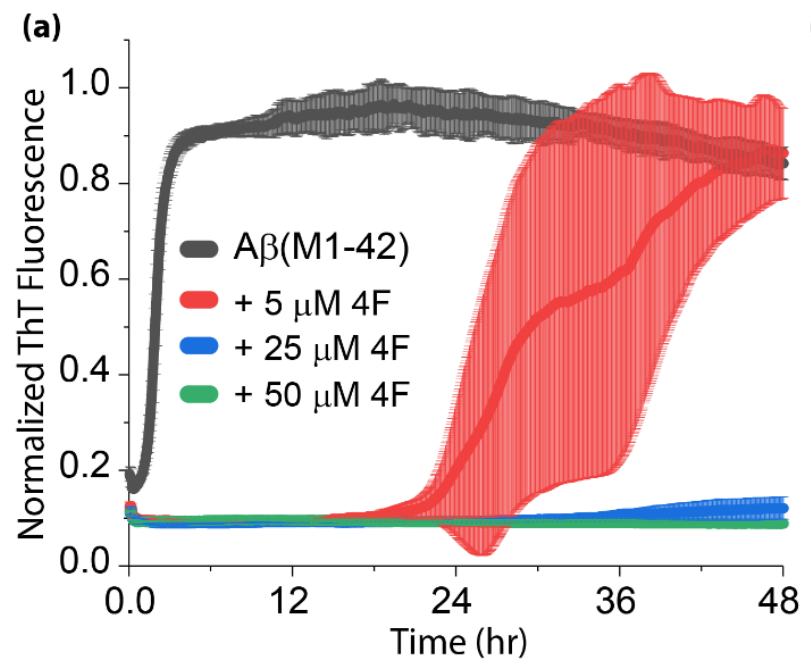

(c)

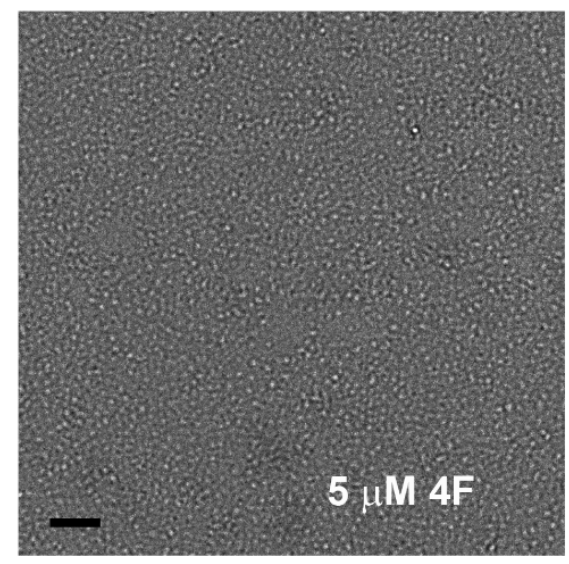

(b)

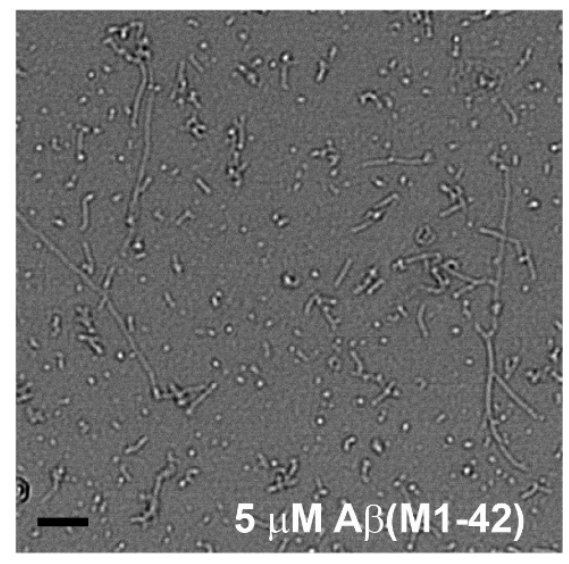

(d)

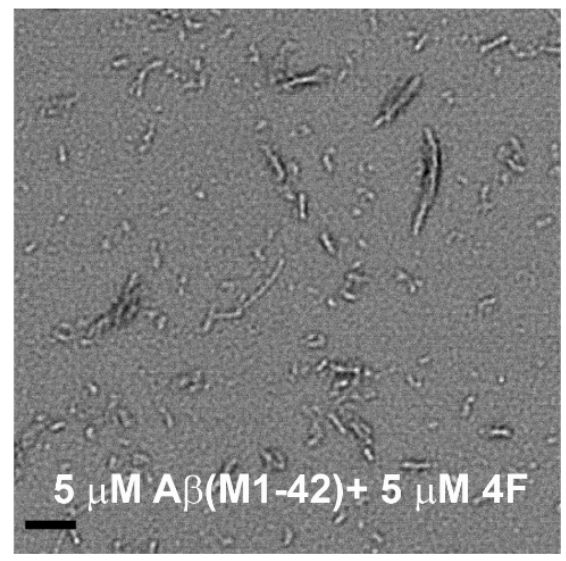

Fig. 1 (a) Time course aggregation kinetics of $5 \mu \mathrm{M} A \beta(M 1-42)$ monitored using ThT fluorescence in presence and absence of $4 \mathrm{~F}$ peptide at variable concentration as indicated in different colors. The average ThT curve of the samples in triplicate are shown in a solid line and standard errors are highlighted in color. (b-d) TEM images of $5 \mu M A \beta(M 1-42)$ with/without equimolar 4F peptide. Samples for TEM experiments were taken from the 96-wells plate used for ThT fluorescence experiments but had no ThT dye. The scale bar is $200 \mathrm{~nm}$.

and retardation in aggregation kinetics (up to 48 hours) were observed for $A \beta(M 1-42)$ which correlate to our previous observations for $A \beta(1-40) .{ }^{28}$ Morphological analysis of the reaction end product by transmission electron microscopy (TEM) displayed a mixture of $A \beta(M 1-42)$ fibers and spherical oligomers in samples without 4F (Fig. 1b). In presence of equimolar 4F, short and comparatively thick fibers of $A \beta(M 1-42)$ were identified that are morphologically different from $4 \mathrm{~F}$ or $A \beta(M 1-42)$ alone in solution (Fig. 1b-d). At $50 \mu M$ 4F, $A \beta(M 1-42)$ showed comparatively very 
small amount of fiber (straight fiber morphology) with few globular oligomers that correlate the ThT observation (Fig. S1). Taken together, the fluorescence and TEM results indicate that the 4F peptide has a more pronounced effect on slowing down $A \beta(M 1-42)$ 's aggregation by generating morphologically distinct species.

\section{F peptide stabilizes the aqueous conformational state of $A \beta(M 1-42)$}

Next, we investigated the inhibitory mechanism of the $4 \mathrm{~F}$ peptide by monitoring the conformational change in $A \beta(M 1-42)$. Freshly prepared $A \beta(M 1-42)$ monomers incubated with or without 4F peptides were analyzed for several days by circular dichroism (CD) and ${ }^{1} \mathrm{H}$ NMR experiments. CD results showed an initial random-coil rich and partially folded structure for $20 \mu \mathrm{M}$ of $A \beta(M 1-42)$ and $4 F$, respectively. Notably, when both peptides were mixed at equimolar ratio (20 $\mu \mathrm{M})$, a prominent $\alpha$-helical conformation characterized by negative peaks located between $\approx 208$ and $\approx 222 \mathrm{~nm}$ was identified (Fig. 2 a) with a substantial increase $(\approx 3$-fold as compared to 4F alone) in the molar ellipticity $(\Theta)$. Time-lapse CD measurements further identified the stability of the $\alpha$-helical structure in $4 \mathrm{~F}-\mathrm{A} \beta(\mathrm{M} 1-42)$ mixed solution with no change in ' $\Theta$ ' and $\mathrm{CD}$ minima for a duration of 2 days (Fig. 2a). Thereafter, a decrease in ' $\Theta$ ' was observed with a negligible change in CD minima possibly due to amyloid fibrillation. Although CD showed a distinct conformational transition in the 4F-A $\beta(M 1-42)$ complex, it was not possible to ascertain which of the two different peptides has contributed to the induction of the experimentally observed $\alpha$-helical secondary structure.

To explore the conformational states exhibited by the two different peptides in the 4F$A \beta(M 1-42)$ mixed solution, we next carried out NMR experiments. The fingerprint amide $\mathrm{N}-\mathrm{H}$ region in proton NMR spectra was used to monitor the conformational state of individual peptides. ${ }^{42}$ As illustrated in Fig. $2 b$, the amide protons showed a distinct chemical shift dispersion for $A \beta(M 1-42)$ and $4 F$. The $A \beta(M 1-42)$ peptide exhibited sharp amide proton peaks in the $\approx 7.5$ to $8.5 \mathrm{ppm}$ region; whereas, the $4 \mathrm{~F}$ peptide showed broad peaks in that region and a distinct isolated 
peak for the indole ring $\mathrm{N}-\mathrm{H}$ proton at $\approx 10 \mathrm{ppm}$. The $\approx 7.5$ to $8.5 \mathrm{ppm}$ region of the NMR spectrum of $A \beta(M 1-42)$ mixed with equimolar $4 F$ showed an NMR peak pattern similar to that of $A \beta(M 1-42)$ alone in solution (Fig. 2c). Since most of the fingerprint region (7.5 to $8.5 \mathrm{ppm}$ ) for $A \beta(\mathrm{M} 1-42)$ remains unchanged after the addition of $4 \mathrm{~F}$, we hypothesize that the random-coil rich $A \beta(M 1-42)$

(a)

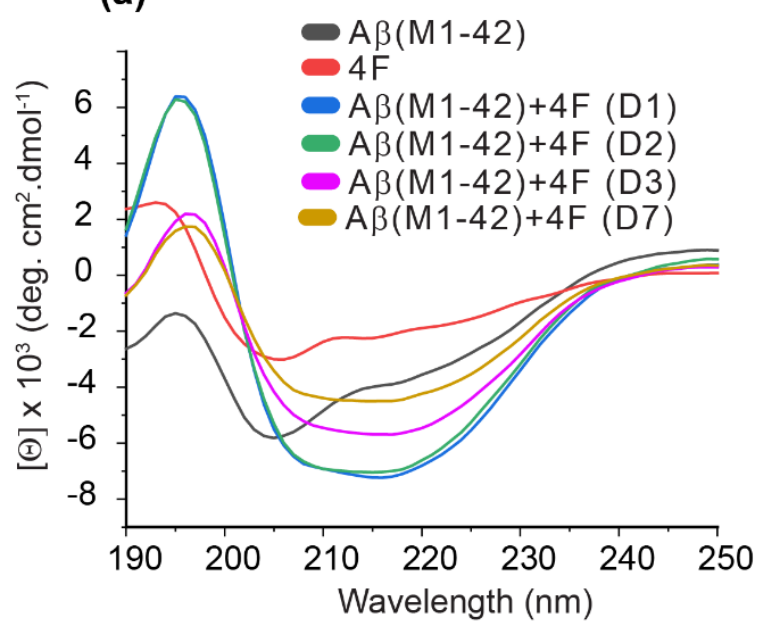

(c)

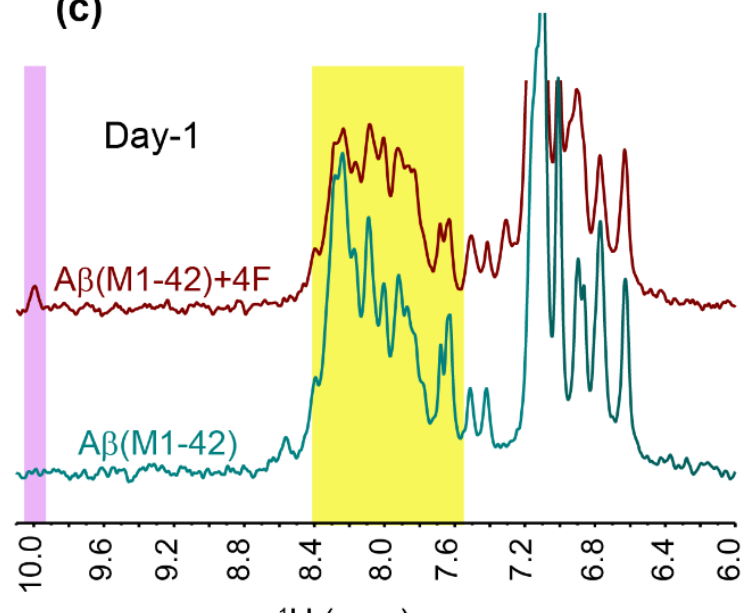

(b)

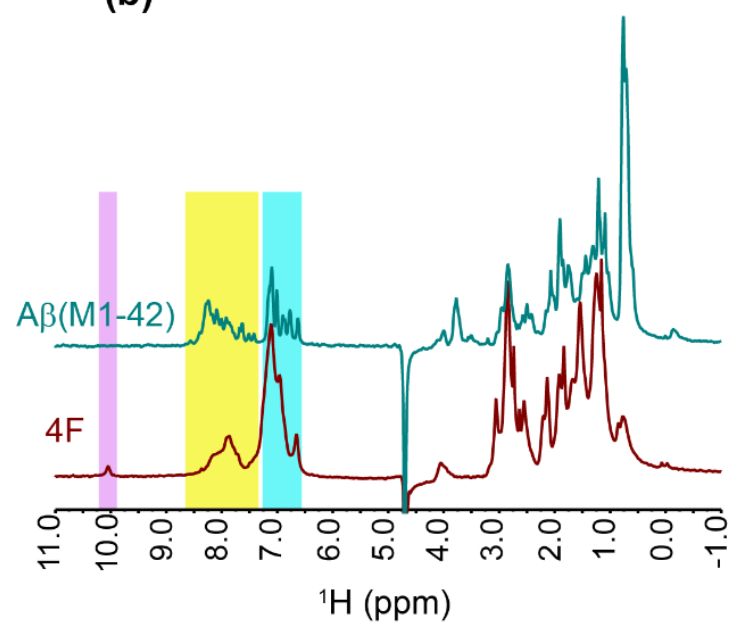

(d)

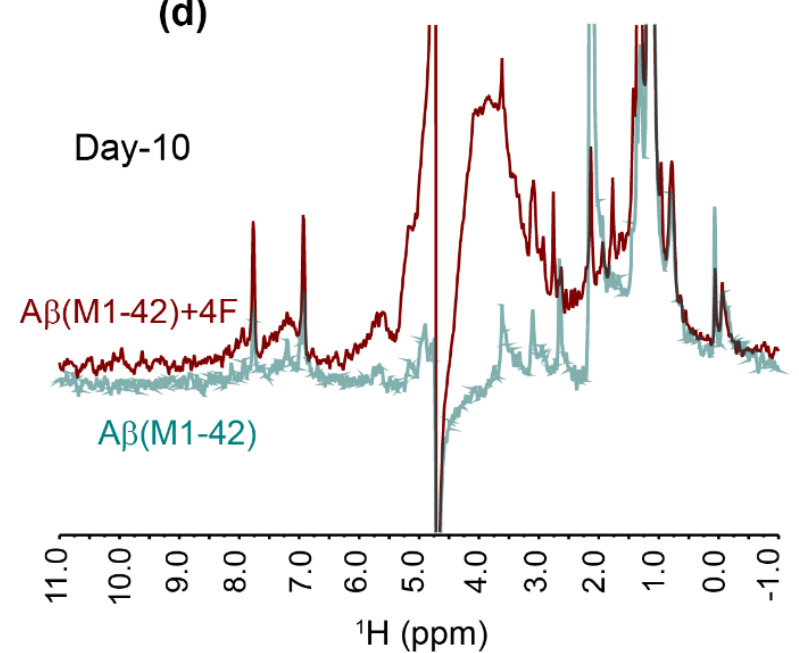

Fig. 2 (a) Time-lapse measurement of conformational change in $20 \mu \mathrm{M} A \beta$ (M1-42) mixed with equimolar 4F peptide using $\mathrm{CD}$ spectroscopy. The samples were incubated at room temperature and CD measurements were carried out until day-7 (denoted as D7). (b) ${ }^{1} \mathrm{H}$ NMR spectra of $20 \mu \mathrm{M} \mathrm{A \beta}$ (M1-42) and 4F peptides. The distinguished amide-proton $(\mathrm{N}-\mathrm{H})$ and $4 \mathrm{~F}$ peptide's Trp indole NH proton peaks are highlighted. (c) ${ }^{1} \mathrm{H}$ NMR spectra illustrate the changes in amide proton resonances in $20 \mu \mathrm{M} \mathrm{A} \beta(\mathrm{M} 1-42)$ mixed with an equimolar 4F peptide. The yellow region highlighted a small change in the $A \beta(M 1-42)$ spectrum pattern mixed with 4F. (d) ${ }^{1} \mathrm{H}$ spectra of NMR samples used for (c) after 10 days incubation under gentle shaking at $37^{\circ} \mathrm{C}$. All NMR spectra were recorded on a $500 \mathrm{MHz}$ NMR spectrometer at $25^{\circ} \mathrm{C}$. 
conformation remained unaffected when bound to $4 \mathrm{~F} .{ }^{42} \mathrm{~A} \beta(\mathrm{M} 1-42)$ peptide alone (with no additives) was incubated for several days to allow for peptide aggregation and the progress was monitored by proton NMR (Fig. 2c and d). Proton NMR spectra recorded on day-10 presented substantial broadening and intensity decrease for most of the peaks (Fig.2d) as compared to day1 (Fig. 2c), indicating $A \beta(M 1-42)$ 's fibrillation both in absence and presence of 4F. Interestingly, proton NMR peaks from 4F including the tryptophan indole ring $\mathrm{N}-\mathrm{H}$ proton (at $\sim 10 \mathrm{ppm}$ as seen in Fig.2b) were absent, and a similar amide proton NMR peak pattern was observed for both
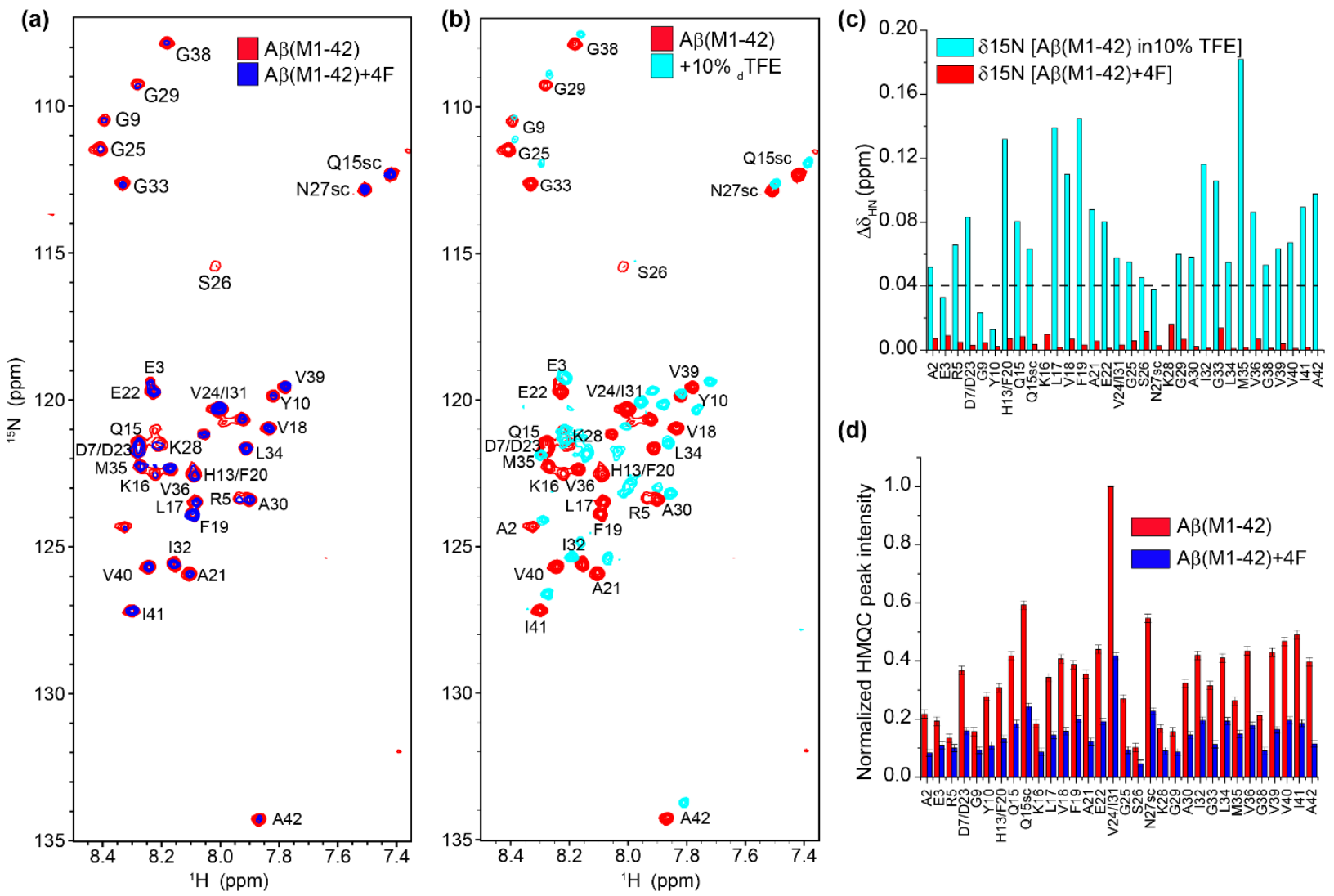

(d)

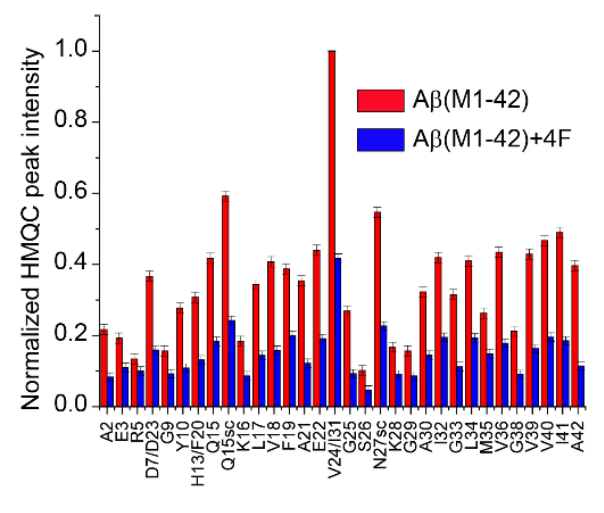

Fig. 3 (a) Superimposed ${ }^{15} \mathrm{~N} /{ }^{1} \mathrm{H}$ SOFAST-HMQC spectra of $20 \mu \mathrm{M}$ uniformly-labelled $\left({ }^{13} \mathrm{C} /{ }^{15} \mathrm{~N}\right)$ $\mathrm{A} \beta$ (M1-42) in $10 \mathrm{mM}$ sodium phosphate, $\mathrm{pH} 7.4$ mixed with (blue) or without (red) equimolar unlabeled $4 \mathrm{~F}$ peptide. (b) ${ }^{15} \mathrm{~N} /{ }^{1} \mathrm{H}$ SOFAST-HMQC spectra illustrating a conformation change in $20 \mu \mathrm{M} \mathrm{A \beta}$ (M1-42) in aqueous buffer (10 mM sodium phosphate, $\mathrm{pH} 7.4$; in red) and buffer containing $10 \%$ deuterated TFE (in cyan). (c) The average chemical shift perturbation $\left(\Delta \delta_{H N}\right)$ calculated from ${ }^{15} \mathrm{~N} /{ }^{1} \mathrm{H}$ SOFAST-HMQC spectra in presence of equimolar $4 \mathrm{~F}$ (Fig. 3A; in red) and $10 \%$ deuterated-TFE (Fig. 3b; in cyan) are plotted as a function of residue number. The dashed line in (c) indicates the average chemical shift perturbation observed for $A \beta(M 1-42)$ residues in $10 \%$ deuterated-TFE. (d) Normalized SOFAST-HMQC NMR peak intensities derived from Fig. 3a. Error bars represent standard error. NMR spectra were obtained NMR spectrometer at $25^{\circ} \mathrm{C}$. 
samples (Fig. 2d). This indicated a likely complexation of 4F peptide molecules with $A \beta(M 1-42)$ fibers. Such aggregates in general exhibit line broadening and are beyond detection by solution NMR. The stability of the complex was further investigated by washing these large aggregates in $2 \mathrm{M} \mathrm{NaCl}$ (see Methods). Tryptophan fluorescence of the filtrate sample, with fluorescence emission at $\approx 458 \mathrm{~nm}$ when excited at $295 \mathrm{~nm}$, confirmed the presence of the $4 \mathrm{~F}$ peptide indicating the disintegration of $4 \mathrm{~F}$ from $\mathrm{A} \beta(\mathrm{M} 1-42)$ fibers (Fig. S2a). However, it did not rule out the possible presence of any $4 \mathrm{~F}$ peptide in $\mathrm{A} \beta(\mathrm{M} 1-42)$ fiber after repeated washing using $2 \mathrm{M} \mathrm{NaCl}$. To explore this, the filtered $A \beta(M 1-42)$ fibers were incubated overnight with $2 \%$ deuterated SDS followed by 30 minutes heating at $80^{\circ} \mathrm{C}$ (see Methods) and used to acquire proton NMR spectra which depicted no characteristic peaks corresponding to 4F; specifically, the SDS treated sample did not show the fingerprint tryptophan indole $\mathrm{N}-\mathrm{H}$ proton (at $\sim 10 \mathrm{ppm}$ ) indicating the absence of $4 \mathrm{~F}$ peptide (Fig. S2b) in filtered $A \beta(M 1-42)$ fibers.

\section{Secondary structure characterization of $A \beta(M 1-42)$ bound to $4 F$ using NMR}

We further investigated the secondary structure of $A \beta(M 1-42)$ bound to $4 F$ in the heteromer state using 2D ${ }^{15} \mathrm{~N} /{ }^{1} \mathrm{H}$ SOFAST-HMQC experiments. For this, we employed an approach to first monitor $A \beta(M 1-42)$ 's the overall secondary structure in two different solvent environments that give rise to a random-coil rich and a partially folded $\alpha$-helix structure. 2D HMQC pattern and $C D$ spectrum observed for $A \beta(M 1-42)$ in $10 \mathrm{mM}$ sodium phosphate buffer resembled that of a random-coil like conformation reported previously (Fig. 3a). ${ }^{43,44}$ In the presence of $10 \%$ deuterated 2,2,2-Trifluoroethanol (TFE), a significant change in $A \beta(M 1-42)$ HMQC pattern and chemical shift was observed (Fig. 3b). Remarkably, a majority of $A \beta(M 1-42){ }^{15} \mathrm{~N} /{ }^{1} \mathrm{H}$ peaks were found to depict upfield chemical shifts in ${ }^{1} \mathrm{H}$ and ${ }^{15} \mathrm{~N}$ dimensions likely indicating $A \beta(M 1-42)$ 's conformational alteration (Fig. 3b). The upfield $\mathrm{H}-\mathrm{N}$ chemical shifts in HMQC spectrum in presence of $10 \%$ TFE also indicated the presence of an $\alpha$-helical $A \beta(M 1-42)$ as compared to its aqueous structure (Fig. 3a), and such chemical shift changes have been observed previously for several other proteins during folding. ${ }^{45}$ Further $C D$ experiments on $A \beta(M 1-42)$ confirmed 
induction of an $\alpha$-helix in $A \beta$ (M1-42) in presence of $10 \%$ TFE (Fig. S3), The random-coil rich $A \beta(M 1-42)$ characterized by a negative peak at $\approx 200 \mathrm{~nm}$ showed an increase in ' $\Theta$ ' and shift in CD minima that resemble an $\alpha$-helical conformation (Fig. 3b). Induction of an a-helical conformation by TFE has also been observed for several short peptides including $A \beta$ and thus correlate with the NMR observations mentioned above. Notably, our comparative study of A $\beta$ (M142) conformation in presence of $10 \%$ TFE and 4F showed a very distinct HMQC pattern (Fig. 3a and b). Although a similar CD spectrum was obtained for $A \beta(M 1-42)$ in presence of $4 \mathrm{~F}$ or $10 \%$ TFE (Figs. 2a and S3), a negligible ${ }^{15} \mathrm{~N} /{ }^{1} \mathrm{H}$ chemical shift change for $A \beta(M 1-42)$ in presence of $4 \mathrm{~F}$ and a substantial change in the presence of $10 \%$ TFE clearly indicated the existence of a randomcoil rich $A \beta(M 1-42)$ bound to $4 F$ (Fig. 3c). A comparison of the average chemical shift perturbation

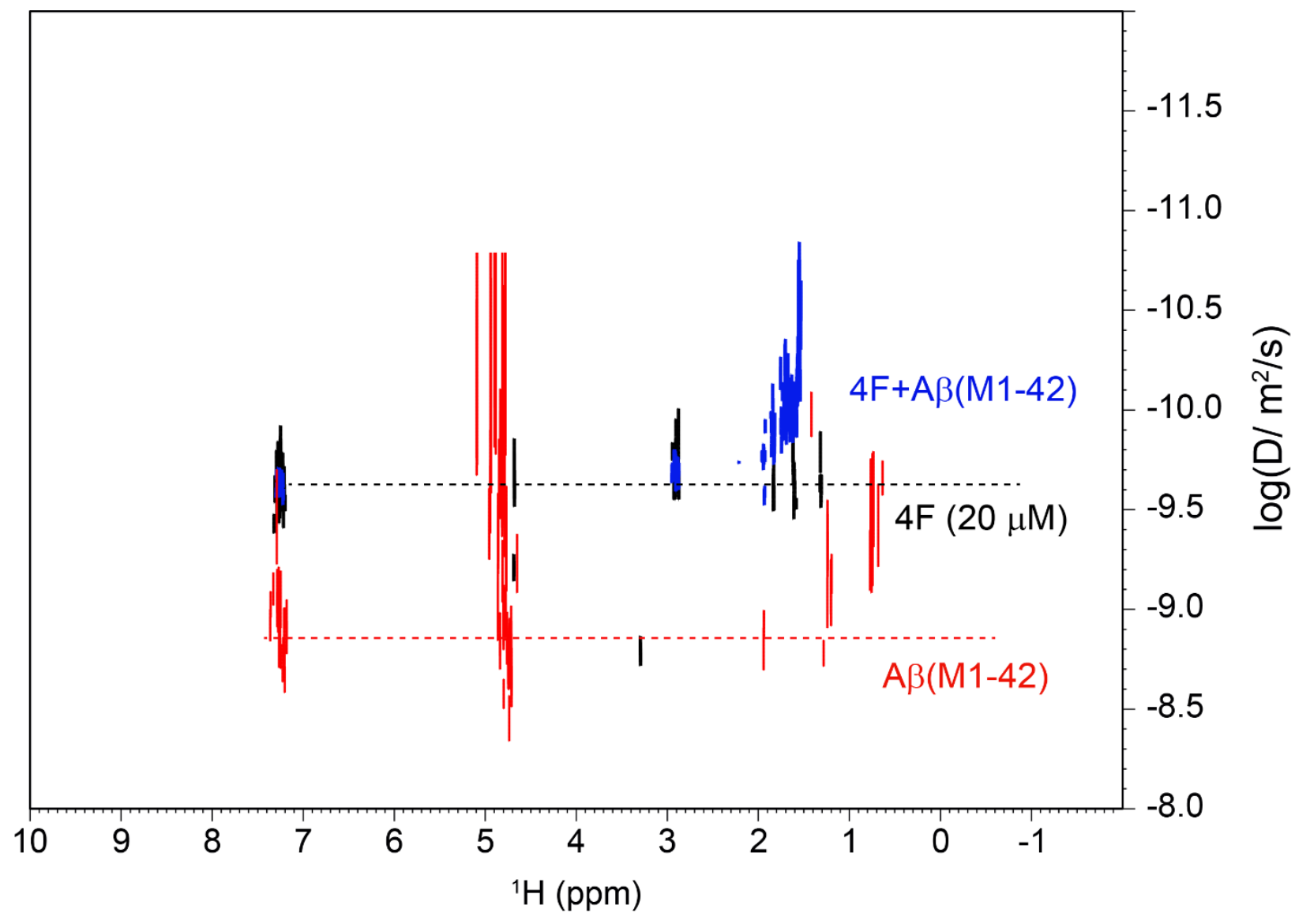

Fig. 4 DOSY spectra of $20 \mu \mathrm{M} 4 \mathrm{~F}$ peptide in absence (black) and presence (blue) of equimolar $A \beta(M 1-42)$ in $100 \% D_{2}$ O. The DOSY spectrum of $20 \mu \mathrm{M} A \beta(M 1-42)$ alone is shown in red. These data were obtained using a $500 \mathrm{MHz}$ NMR spectrometer at $25^{\circ} \mathrm{C}$. 
$\left(\Delta \delta_{H N}\right)$ showed a majority of the $A \beta(\mathrm{M} 1-42)$ residues have a chemical shift perturbation above the cut-off value in presence of $10 \%$ TFE; on the other hand, in presence of equimolar $4 \mathrm{~F}$ the $\Delta \delta_{H N}$ value is negligible (Fig. 3c). Taken together, the NMR and CD results confirmed the strongly binding of $4 F$ to $A \beta(M 1-42)$ to restrains $A \beta(M 1-42)$ 's conformational alteration, thereby indicating the mechanism of retardation of $A \beta(M 1-42)$ 's amyloid aggregation.

\section{Atomistic insights into $4 F$ and $A \beta(M 1-42)$ complex formation}

(1)

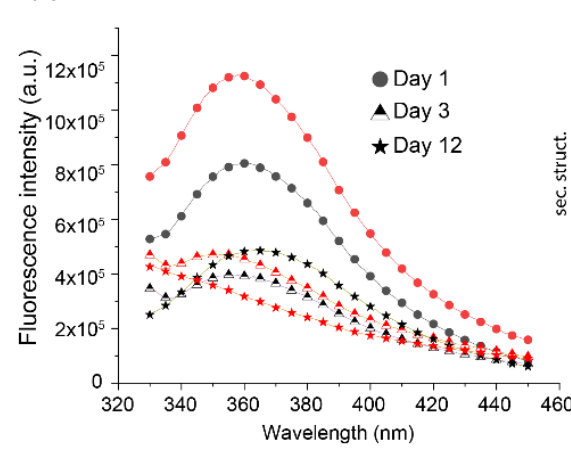

(b)

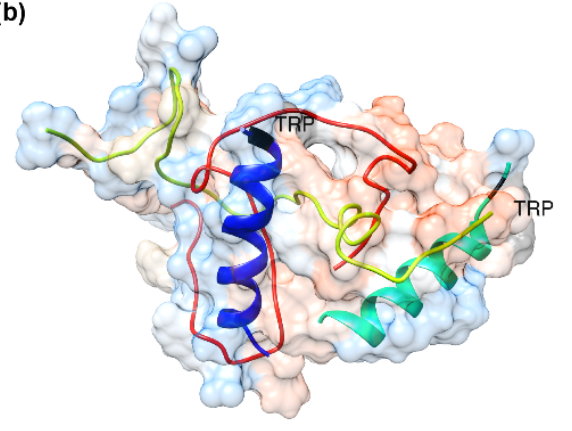

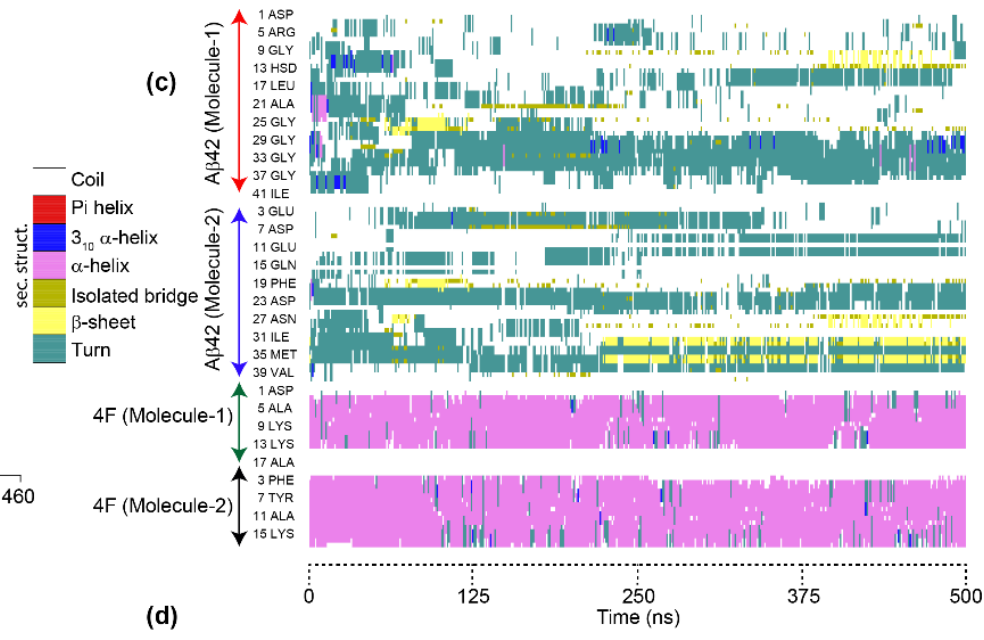

(d)
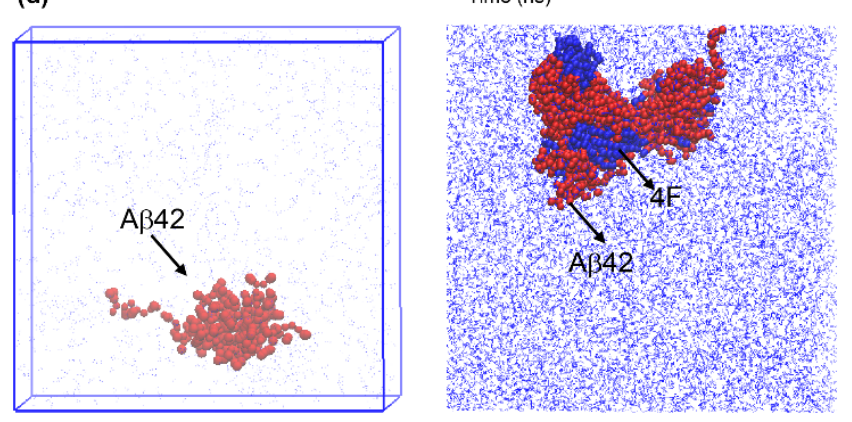

Fig. 5 (a) Time-lapse tryptophan emission spectra of $5 \mu \mathrm{M} 4 \mathrm{~F}$ peptide in absence (black) or presence (red) of equimolar $A \beta(M 1-42)$ excited at $295 \mathrm{~nm}$. The background fluorescence of the buffer are subtracted to correct spectra and are recorded in arbitrary units (a.u.). The samples are incubated at room temperature and fluorescence spectra are recorded for several days as indicated in different symbols at $25^{\circ} \mathrm{C}$. (b) MD snapshot illustrating interaction between 2 molecules of $\mathrm{A} \beta 42$ and $4 \mathrm{~F}$ peptide (in cartoon) colored in yellow/red and blue/cyan, respectively. The molecular surface shows an increase in hydrophobicity from blue to orange. (c) The secondary structure evolution map of 4F-A 42 complex derived from $0.5 \mu \mathrm{s}$ MD simulation as a function of amino acids. The secondary structure units are shown on the left (c). (d) Coarse-grained MD snapshots illustrating aggregation of 10 molecules A 342 (left) and hetero-aggregation complex of 4F-A 42 (right). The A 42 and $4 \mathrm{~F}$ are shown in red and blue, respectively. 
The binding interactions and complex formation between $4 \mathrm{~F}$ and $\mathrm{A} \beta(\mathrm{M} 1-42)$ at the atomic level was next investigated using 2D ${ }^{15} \mathrm{~N} /{ }^{1} \mathrm{H}$ SOFAST-HMQC NMR experiments. $20 \mu \mathrm{M}$ uniformly ${ }^{13} \mathrm{C} /{ }^{15} \mathrm{~N}$ labeled $\mathrm{A} \beta(\mathrm{M} 1-42)$ in presence of equimolar $4 \mathrm{~F}$ peptide exhibited a substantial reduction in the overall intensity for most of the residues in the $2 \mathrm{D}{ }^{15} \mathrm{~N} /{ }^{1} \mathrm{H}$ SOFAST-HMQC spectrum (Fig. 3). $A \beta(M 1-42) A \beta(M 1-42)$ Notably, no significant difference in the chemical shifts of $A \beta(M 1-42)$ residues was observed indicating a negligible or no change in the $A \beta(M 1-42)$ conformation when bound to $4 \mathrm{~F}$ (Fig. 3c). This observation is in good agreement with the above described CD and ${ }^{1} \mathrm{H}$ NMR results $A \beta(M 1-42)$ shown in Fig. 2. On the other hand, the ${ }^{13} \mathrm{C} /{ }^{1} \mathrm{H}$ correlation spectrum of $A \beta(M 1-42)$ revealed the disappearance of resonance from the aromatic side chains of Phe and Tyr when mixed with equimolar 4F (Fig. S4). This observation indicates hydrophobic $\pi-\pi$ packing could be the driving force for the complex formation between $A \beta(M 1-42)$ and 4F peptides. The uniform reduction in the NMR signal intensities in the $2 \mathrm{D}{ }^{15} \mathrm{~N} /{ }^{1} \mathrm{H}$ SOFAST-HMQC most likely due to a reduction in $A \beta(M 1-42)$ the mobility of $A \beta(M 1-42)$ residues when complexed with $4 F$ which enhances the spin-spin relaxation and therefore broadens the observed NMR resonances. To further confirm this observation, we determined the diffusion rates of $4 \mathrm{~F}$ mixed with and without equimolar $A \beta(M 1-42)$ using diffusion ordered NMR spectroscopy (DOSY). $20 \mu M$ 4F peptide in $100 \% D_{2} \mathrm{O}$ showed a diffusion constant of $\approx 9.65 \mathrm{~m}^{2} \mathrm{~s}^{-1}$, whereas $A \beta(M 1-42)$ diffused faster with a diffusion rate constant of $\approx 8.93 \mathrm{~m}^{2} \mathrm{~s}^{-1}$ (Fig. 4). Unlike the $4 \mathrm{~F}$ peptide, the diffusion pattern observed for $A \beta(M 1-42)$ was found to be inhomogeneous due to the inherent nature of its aggregation during the NMR data acquisition ( $\approx 10$ hours) (Figs. 4 and S5). Particularly, the 4F-A (M1-42) mixed sample showed a diffusion pattern like that of the $4 \mathrm{~F}$ indicating the presence of small-sized water soluble hetero-oligomers.

\section{Atomistic interaction between $A \beta(M 1-42)$ and $4 F$ revealed using $M D$ simulation}

Next, we investigated the binding orientation of $4 F$ peptide to $A \beta(M 1-42)$ using tryptophan fluorescence. The fluorescence emission of $5 \mu \mathrm{M} 4 \mathrm{~F}$ peptide (W2) was monitored for several days 
in presence and absence of equimolar $A \beta(M 1-42)$. In the absence of $A \beta(M 1-42)$, excitation of $W 2$ residue in $4 \mathrm{~F}$ at $295 \mathrm{~nm}$ showed fluorescent emission at $\lambda_{\max } \approx 358 \mathrm{~nm}$ indicating its exposure to a polar environment (Fig. 5a). The 4F peptide mixed with equimolar concentration of $A \beta(M 1-42)$ showed an increase in W2 fluorescence with no significant spectral shift on day-1. However, differences were noticed on day-3 with a significant blue shift in W2 emission only in presence of $A \beta(M 1-42)$ indicating a non-polar environment of $W 2$ in the $A \beta-4 F$ complex (Fig. 5a). Further incubation of these samples depicted disappearance of $\lambda_{\max }$ peak in $A \beta-4 F$ mixture on day-12 indicating the $4 \mathrm{~F}$ peptides' orientation in $A \beta(M 1-42)$ fibers exposing its $W 2$ to the hydrophobic region of amyloid fibers. Such observations were previously observed for $4 \mathrm{~F}$ peptide interacting with $A \beta$ (1-40) indicating their preferential binding to $A \beta$ peptides irrespective of their hydrophobicity. ${ }^{28}$

In an attempt to better understand the spatial orientation of $4 \mathrm{~F}$ when bound to $A \beta(1-42)$, we next performed hundreds of nanosecond all-atom molecular dynamics (MD) simulations. A significant secondary structural transition was identified in the partially folded $A \beta(1-42) N M R$ structures (PDB ID: 1Z0Q) simulated in presence of 2 molecules of $4 \mathrm{~F}$ (initially placed $\sim 0.5 \mathrm{~nm}$ away from $A \beta$ ) at the end of a $0.5 \mu$ s MD simulation. Both $A \beta$ molecules depicted a random-coil conformation and were found to be tightly coupled with 4F with an ideal helix conformation (Fig. $5 b)$. Secondary structure evolution map showed $A \beta$ molecules mostly rendered random-coil or turns with a short transient $\beta$-sheet or $3_{10} \alpha$-helical structure when complexed with $4 \mathrm{~F}$. The atomistic structural model correlated well with CD and NMR observations described above that suggested a possible unstructured $A \beta(M 1-42)$ conformation when bound to 4F. In addition, the experimental observation of W2 spatial arrangement with an exposure to a non-polar environment was identified in the atomistic model of tetrameric structure that showed the W2 residues are buried inside the hydrophobic regions (Fig. 5b). The interacting residues in the 4F-A $\beta(1-42)$ complex are listed in Table S1, which shows interaction sites that involve both $\mathrm{N}$ - and C-termini 
residues including central hydrophobic residues in $A \beta(1-42)$. This result correlates with the average chemical shift perturbation obtained from ${ }^{15} \mathrm{~N} /{ }^{1} \mathrm{H}$ SOFAST-HMQC NMR. Importantly MD calculations showed the formation of two salt-bridges between D7-K13 and K16-E16 in the 4F$A \beta(M 1-42)$ complex. Several other interactions that include hydrogen bonds, alkyl and $\pi$-alkyl interactions are also identified in the 4F-A $(\mathrm{M} 1-42)$ complex and are listed in Table S1. Multimicrosecond MD simulation using coarse-grained models of 10 molecules of $A \beta(1-42)$ distributed randomly showed an aggregated self-assembled complex at the end of $5 \mu \mathrm{s}$ MD simulation (Fig. $5 d$, left). Interestingly, a random distribution of 10 molecules of $A \beta(1-42)$ and $4 F$ exhibited heterogenic assembly with $4 \mathrm{~F}$ peptides buried inside $A \beta(M 1-42)$ oligomers (Fig. 5d, right). Notably, just as $A \beta(1-42)$ self-assembling generates a single large particle, the spontaneous assembly of $A \beta(1-42)$ and $4 \mathrm{~F}$ produced a single heteromer complex (Fig. $5 \mathrm{~d}$ ) which correlates with the NMR observation of line-broadening and a uniform reduction in NMR signal intensity due to heteromerization (Fig. $4 a$ and b). MM/PBSA approach estimated the free binding energy in the 4F-A $\beta(M 1-42)$ complex system. Although the MM/PBSA could not exactly imitate the experimental binding free energy, it could provide a comparative energy map by breaking down the free energy components that govern the complex formation. The $4 \mathrm{~F}-\mathrm{A} \beta(1-42)$ complex formation was found to be favored by Coulombic $\left(\Delta \mathrm{G}_{\text {coul }}\right)$, van der Waals $\left(\Delta \mathrm{G}_{\mathrm{vdw}}\right)$ and non-polar solvation terms $\left(\Delta G_{n p s}\right)$, whereas the polar solvation energy $\left(\Delta G_{p s}\right)$ opposed the complex formation (Table 1). These findings correlate well with the observed interacting residues between $\mathrm{A} \beta(1-42)$ and $4 \mathrm{~F}$ contributing through salt-bridges and hydrogen bonds.

Table 1. MM/PBSA based binding free energy $\left(\mathrm{kcal} \mathrm{mol}^{-1}\right)$ calculation.

\begin{tabular}{|c|c|c|c|c|c|c|c|}
\hline \multirow[t]{2}{*}{ System } & \multirow[b]{2}{*}{${ }^{1} \Delta G_{\text {bind }}$} & \multicolumn{2}{|c|}{ Polar Contribution } & \multicolumn{3}{|c|}{ Non-polar Contribution } & \multirow[b]{2}{*}{${ }^{7} \Delta G_{\text {nonpolar }}$} \\
\hline & & ${ }^{2} \Delta G_{\text {coul }}$ & ${ }^{3} \Delta G_{p s}$ & ${ }^{4} \Delta G_{\text {polar }}$ & ${ }^{5} \Delta \mathbf{G}_{\mathrm{vdw}}$ & ${ }^{6} \Delta \mathbf{G}_{\mathrm{nps}}$ & \\
\hline$A \beta(M 1-42)+4 F$ & $-27.3 \pm 13.9$ & $-284.6 \pm 73.4$ & $384.9 \pm 77.1$ & 100.3 & $-110.1 \pm 10.5$ & $-17.5 \pm 0.9$ & -127.6 \\
\hline
\end{tabular}




\section{apoA-I mimetic peptide bound $A \beta(M 1-42)$ is neurotoxic}

Controlling the neurotoxicity of $A \beta(1-42)$ has remained a dominant research area in $A D$. Design and discovery of short peptide inhibitors for $A \beta(1-42)$ are studied intensively. In this study, we also tested the impact of $4 \mathrm{~F}$ peptide on the neurotoxicity of $A \beta(M 1-42)$ in differentiated $S H-S Y 5 Y$ neuroblastoma cells. Compared to the F-12 cell media, 4F peptide alone was found to be slightly but statistically insignificant neurotoxic (Fig. 6a) as previously observed for the full-length apoA-I. ${ }^{15}$ In contrast, high concentration 4F peptide increased cell proliferation in undifferentiated SH-SY5Y cells (Fig. S6). Although, a direct comparison of 4F's cell toxicity on differentiated and undifferentiated cells is difficult, the differentiation of SH-SY5Y cells elevates 4F's toxicity. A similar, differential phenotype between differentiated and undifferentiated rat neuronal cells treated with $A \beta$ peptides has been reported. ${ }^{46}$ Remarkably, our results show that the $A \beta(M 1-42)$ complexed with $4 F$ peptides exhibited higher neurotoxicity that $A \beta$ alone. When $5 \mu \mathrm{M}$ of $A \beta(M 1-42)$ monomers was used to treat differentiated SH-SY5Y cells, a cell viability of $\approx 75 \%$ was observed; and $5 \mu \mathrm{M}$ of $\mathrm{A} \beta(\mathrm{M} 1-42)$ complexed with two or ten excess molar of $4 \mathrm{~F}$ showed a reduction in viability of $\approx 65 \%$ and $45 \%$, respectively (Fig. $6 a$ ). The MTT based cell-viability measurement on day-8 indicated that 4F generates toxic hetero-oligomers when complexed with $A \beta(M 1-42)$. Further fluorescence imaging of $A \beta(M 1-42)$ treated SH-SY5Y cells presented distinct morphological phenotypes in neurites in the presence and absence of $4 \mathrm{~F}$. The wellbranched and connected SH-SY5Y cells observed on day-1 showed a gradual depletion in neurite outgrowth and connectivity treated with nocodazole, which is known to disrupt neurite growth and cause apoptosis (Fig. 6b and c). As compared to SH-SY5Y cell morphology observed in nocodazole and F12 on Day-8, cells treated with 10 or $50 \mu \mathrm{M}$ 4F peptide showed well-connected cells with more polarized 
soma cell bodies. In contrast to the MTT data, 4F mixed with $A \beta(M 1-42)$ did not significantly change neurite density, indicating either $A \beta(M 1-42)+4 F$ induces changes in neurite morphology that are beyond the limits of detection in our assay or that cells are in the early stages of cytotoxic death. However, considering the MTT reduction assay that is commonly used to study A $\beta$ toxicity in single cell cultures with high reproducibility, ${ }^{47}$ the observed results can be interpreted as $4 \mathrm{~F}$ retards $A \beta(M 1-42)$ aggregation
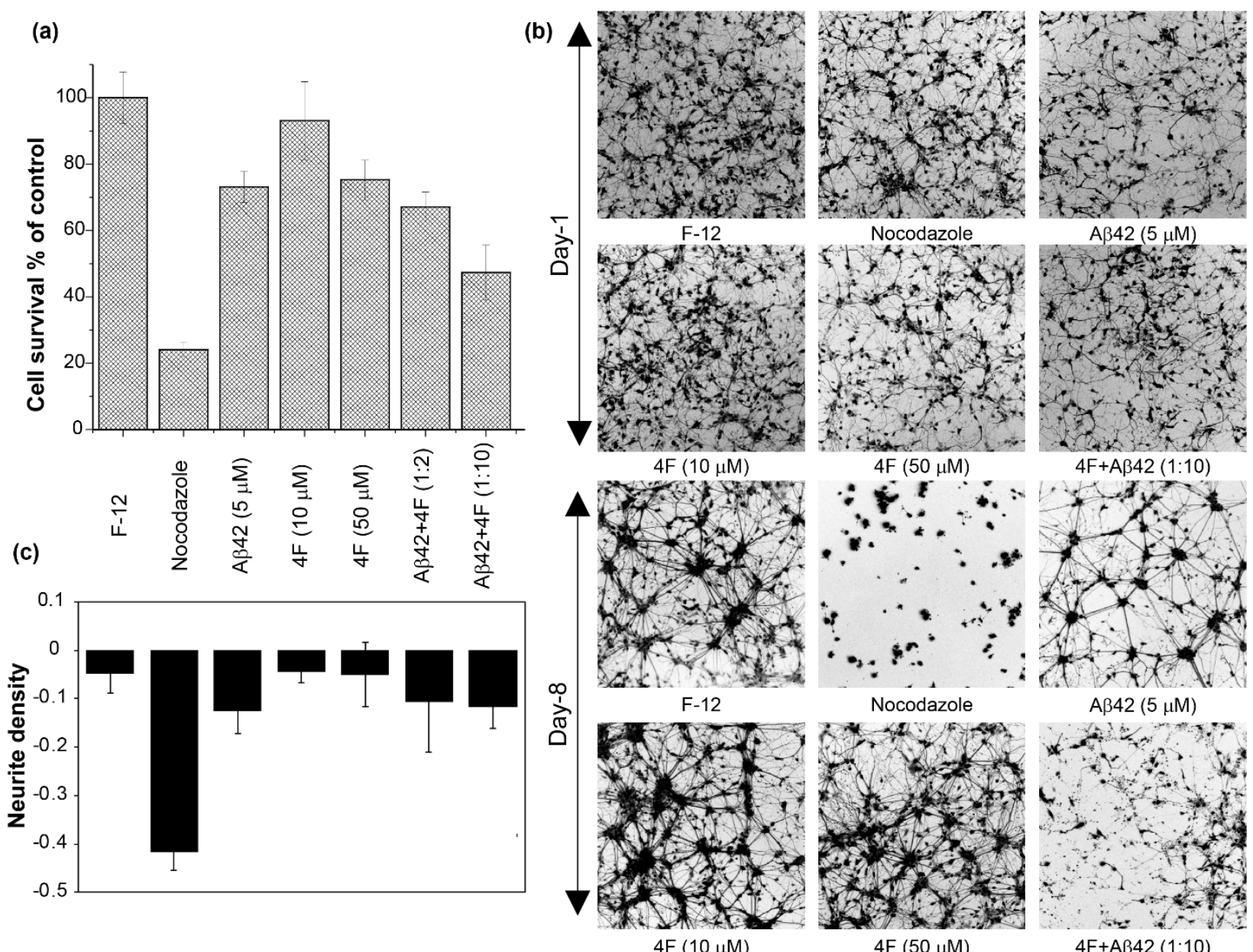

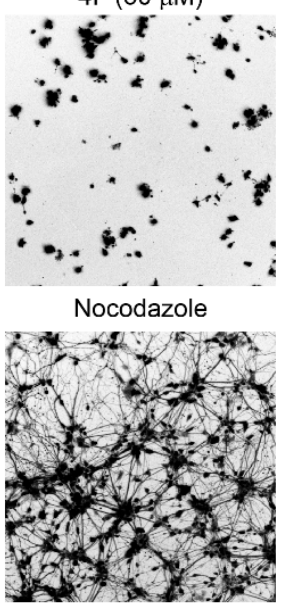

$4 \mathrm{~F}(50 \mu \mathrm{M})$

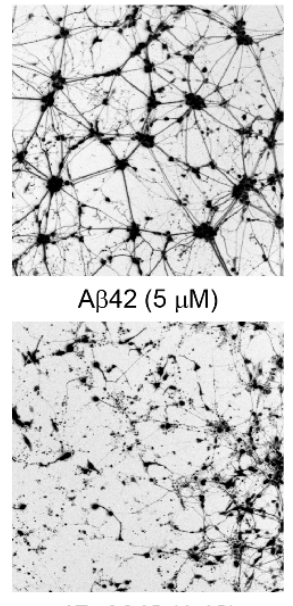

$4 \mathrm{~F}+\mathrm{A} \beta 42(1: 10)$

Fig. 6 (a) Differentiated SH-SY5Y cell viability determined by MTT assay of $5 \mu M A \beta(M 1-$ 42)(denoted as $A \beta 42$ ) incubated with 4F peptide at a variable concentration after 8 days. The cellviability profiles are normalized using the \% of live cells present in F-12 media without any additives. Shown are standard error from five replicates. (b) Fluorescence imaging of differentiated SH-SY5Y cells treated with $A \beta$ (M1-42), 4F or mixture as described in Fig. 6A. Images were collected after treating cells on Day-1 and Day-8. Nocodazole is used as a positive control that shows significant damage in neurite growth. The cell-assay experiments were carried out by pre-incubating $A \beta(M 1-$ 42) with $4 \mathrm{~F}$ peptide at room temperature in $10 \mathrm{mM} \mathrm{NaPi}, \mathrm{pH}$ 7.4. (c) Quantification of images from Fig.6b using NeurphologyJ to measure neurite density at each time point. Bars represent the average change in neurite density after treatment. Errors bars represent standard errors. 
by generating a toxic hetero-oligomer species. This is in agreement with a previous finding that apolipoprotein fragments and $A \beta(1-42)$ form toxic oligomers.

In summary, the apoA-I mimetic $4 \mathrm{~F}$ peptide used in this study serves as an excellent model to explore the role of apolipoproteins or their fragments in modulating pathologically misfolded amyloidogenic $A \beta(1-42)$ associated with $A D$. 4F shows a strong binding affinity for $A \beta(M 1-42)$ and is capable of retarding its aggregation. The hetero-oligomerization between $4 \mathrm{~F}$ and $\mathrm{A} \beta(\mathrm{M} 1-42)$ generates water-soluble aggregates comprising of an unstructured $A \beta(M 1-42)$ and structured $4 \mathrm{~F}$ that are found to be neurotoxic. While the $4 \mathrm{~F}$ peptide was found to have protective role in proliferating cells, it's association with amyloidogenic $A \beta(M 1-42)$ cause generation of cytotoxins. This finding strongly correlates between apolipoprotein fragmentations in brains thereby driving the disease progression. Taken together, the results based on our model study reported here urge further identification and characterization of natural apolipoprotein and its fragments in AD patients to aid in the development of chemical tools that can be used to reduce cellular toxicity.

\section{Experimental procedures}

\section{Expression, purification and synthesis of peptides}

The unlabeled Aß(M1-42) (MDAEFRHDSGYEVHHQKLVFFAEDVGSNKGAIIGLMVGGVVIA) with an extra methionine at the N-terminus was recombinantly expressed in E. coli BL21 (DE3) pLysS Star in LB media as described elsewhere. ${ }^{48}$ The plasmid of $A \beta(M 1-42)$ was obtained from the Nowick laboratory at the University of California, Irvine, USA. Uniformly ${ }^{13} \mathrm{C}$ and ${ }^{15} \mathrm{~N}$ isotope labelled $\mathrm{A} \beta(\mathrm{M} 1-$ 42) was expressed by exchanging LB medium with $\mathrm{M} 9$ minimal medium containing ${ }^{15} \mathrm{NH}_{4} \mathrm{Cl}$ and $\mathrm{D}$ Glucose- ${ }^{13} \mathrm{C}_{6}$. We followed a published protocol to express ${ }^{15} \mathrm{~N}$ labelled $A \beta(M 1-42) .{ }^{48}$ The purified A $(\mathrm{M} 1-42)$ peptide powder $(\approx 1 \mathrm{mg} / \mathrm{mL})$ was treated with $5 \% \mathrm{NH}_{4} \mathrm{OH}$ and aliquots of $\approx 0.1 \mathrm{mg} / \mathrm{mL}$ peptide were prepared after lyophilization. The lyophilized powder samples were re-suspended in the working buffer and vortexed for $15 \mathrm{~s}$ followed by sonication for $15 \mathrm{~s}$ in an ultrasonic bath sonicator. The small aggregates were next removed by centrifuging the sonicated peptide sample at 12,000 rpm for 5 minutes at $4^{\circ} \mathrm{C}$. The $4 \mathrm{~F}$ peptide (Ac-DWFKAFYDKVAEKFKEAF-NH2) was synthesized by solid-phase 
from L-amino acids and purified by HPLC as described previously. ${ }^{29,49} 10 \mathrm{mM}$ sodium phosphate (NaPi) buffer, $\mathrm{pH} 7.4$ was used to dissolve $A \beta(M 1-42)$ and was used for all experiments (until and unless specified).

\section{Peptide aggregation assay using ThT fluorescence}

The aggregation kinetics of $5 \mu \mathrm{M} A \beta(\mathrm{M} 1-42)$ was monitored using $10 \mu \mathrm{M}$ ThT fluorescence in the presence of varying concentrations of $4 \mathrm{~F}$ peptide. A 96-well polystyrene plate was used with a sample volume of $100 \mu \mathrm{L} /$ well in triplicate for all experiments. The aggregation kinetics were monitored using a microplate reader (Biotek Synergy 2) with slow shaking at $37^{\circ} \mathrm{C}$ for 48 hours. The data were recorded at 3 minutes time interval with excitation and emission wavelengths at 440 and $485 \mathrm{~nm}$, respectively. The averages of three replicates were plotted with respect to time.

\section{Transmission Electron Microscopy}

TEM images of $5 \mu \mathrm{M} \mathrm{A \beta (M1-42)}$ incubated with 1 or 10 molar excess $4 \mathrm{~F}$ peptide were taken using a HITACHI H-7650 transmission microscope (Hitachi, Tokyo, Japan) at $25^{\circ} \mathrm{C}$. The samples used for TEM analysis were collected from the 96 -well plate at the end of 48 hours (peptides without the ThT dye). $20 \mu \mathrm{L} / 100 \mu \mathrm{L}$ of sample volume were transferred to a collodion-coated copper grid and incubated for 5 minutes at room temperature followed by three rinses with $20 \mu \mathrm{L}$ of double deionized water to remove buffer salts. The copper grid containing sample was next stained with $4 \mathrm{~mL}$ of $2 \%(\mathrm{w} / \mathrm{v})$ uranyl acetate and incubated for 2 minutes followed by three rinses with $20 \mu \mathrm{L}$ of double deionized water. The copper grid was next allowed to dry overnight under a vacuum desiccator at room temperature.

\section{Circular dichroism}

Far-UV CD experiments were carried out for $20 \mu \mathrm{M} A \beta(\mathrm{M} 1-42)$ dissolved in $10 \mathrm{mM} \mathrm{NaPi}$ in presence and absence of equimolar $4 \mathrm{~F}$ at $25^{\circ} \mathrm{C}$ using a JASCO (J820) spectropolarimeter. A $1 \mathrm{~mm}$ light-path length quartz cuvette containing $200 \mu \mathrm{L}$ of sample was used for CD measurements. CD spectra of $20 \mu \mathrm{M}$ of $\mathrm{A} \beta(\mathrm{M} 1-42)$ or $4 \mathrm{~F}$ in absence of any additives were recorded and used as 
reference/control spectra. $C D$ spectrum of $10 \mu \mathrm{M}$ of $A \beta(M 1-42)$ titrated with $10 \%$ TFE was measured for comparative structural analysis. All samples were incubated at room temperature for time-lapse measurements.

\section{Tryptophan fluorescence}

Tryptophan fluorescence was measured for $5 \mu \mathrm{M}$ 4F peptide mixed with equimolar $\mathrm{A} \beta(\mathrm{M} 1-42)$ using a FluoroMax $4 \circledast$ from HoribaScientific $\circledR$ in continuous mode at $25^{\circ} \mathrm{C}$. The tryptophan was excited at $295 \mathrm{~nm}$ and the fluorescence emission was recorded from 330 to $450 \mathrm{~nm}$ (with a 5-nm bandwidth) with a delay time of 1 min per five scans using a $200-\mu \mathrm{L}$ cuvette. The changes in fluorescence were monitored with respect to $4 \mathrm{~F}$ peptide alone in the absence of $A \beta(M 1-42)$. All samples were incubated at room temperature for time-lapse measurements.

\section{NMR spectroscopy}

All NMR samples were prepared in $10 \mathrm{mM} \mathrm{NaPi}$ buffer, pH 7.4 containing 10\% deuterated water (v/v). Proton NMR spectra were acquired for unlabeled $20 \mu \mathrm{M} A \beta(M 1-42), 20 \mu \mathrm{M} 4 \mathrm{~F}$ and an equimolar $(20 \mu \mathrm{M})$ mixture of $A \beta(M 1-42)$ and $4 \mathrm{~F}$ using a $500 \mathrm{MHz}$ NMR spectrometer at $25^{\circ} \mathrm{C}$. The NMR solution samples were next incubated under gentle agitation for 10 days before acquiring proton NMR spectra. The agitated 4F- $A \beta(M 1-42)$ mixed sample was next filtered using a $0.5 \mathrm{~mL} 30 \mathrm{kDa}$ centrifugal filter (Amicon ${ }^{\circledR}$ Ultra-15) by adding $2 \mathrm{M} \mathrm{NaCl}$ to remove electrostatically bound or free peptides from the solution. The washed buffer was collected, and tryptophan fluorescence was carried out to observe the presence of $4 \mathrm{~F}$. The filtered large aggregates/fibers were next treated with $2 \%$ deuterated SDS (v/v) and the sample was heated at $80^{\circ} \mathrm{C}$ for 30 minutes to dissolve the fibers. Proton NMR spectra of the SDS treated sample was then acquired at $25^{\circ} \mathrm{C}$.

2D heteronuclear ${ }^{15} \mathrm{~N} /{ }^{1} \mathrm{H}$ and ${ }^{13} \mathrm{C} /{ }^{1} \mathrm{H}$ (region of aromatic resonances) SOFAST-HMQC NMR experiments $^{50}$ were carried out for uniformly labelled $20 \mu \mathrm{M} A \beta(\mathrm{M} 1-42)$ in presence and absence of equimolar 4F in $10 \mathrm{mM} \mathrm{NaPi}$, pH 7.4 containing $10 \%$ deuterated water (v/v). The 2D NMR experiments were recorded at $25^{\circ} \mathrm{C}$ on a $800 \mathrm{MHz}$ NMR spectrometer equipped with a $5 \mathrm{~mm}$ triple-resonance inverse 
detection $\mathrm{TCl}$ cryoprobe using 16 scans, $256 \mathrm{t} 1$ increments and a $0.2 \mathrm{~s}$ recycle delay. For comparative structural study, the ${ }^{15} \mathrm{~N} /{ }^{1} \mathrm{H} H \mathrm{HQC}$ titration experiment was carried out for $20 \mu \mathrm{M} \mathrm{A}(\mathrm{M} 1-42)$ dissolved in $10 \mathrm{mM} \mathrm{NaPi}$, pH 7.4 containing $10 \% \mathrm{D}_{2} \mathrm{O}$ and $10 \%$ deuterated 2,2,2 TFE (v/v). Diffusion Ordered SpectroscopY (DOSY) spectra were recorded using stimulated-echo with bipolar gradient pulses for diffusion with a gradient strength increment from 2 to $98 \%$ at $25^{\circ} \mathrm{C}$ on a $500 \mathrm{MHz} \mathrm{NMR}$ spectrometer. NMR spectra were acquired with 16 gradient strength increments, 36,000 time domain data points in the t2 dimension, 3s recycle delay, and 100 ms diffusion delay. DOSY spectra were recorded for samples containing $20 \mu \mathrm{M} A \beta(\mathrm{M} 1-42), 20 \mu \mathrm{M} 4 \mathrm{~F}$ or an equimolar mixture of both peptides (1:1) dissolved in $100 \% \mathrm{D}_{2} \mathrm{O}$.

\section{Cell viability assay}

The cell-viability of human neuroblastoma (SH-SY5Y) cells was measured using MTT cell proliferation assay (Promega, G4000). SH-SY5Y cells were plated in a 96-well plate followed by differentiation in Neurobasal-A, GlutaMAX, B27, 1\% penicillin/streptomycin, and $10 \mu \mathrm{M}$ retinoic acid in a $5 \% \mathrm{CO}_{2}$ humidified incubator at $37^{\circ} \mathrm{C}$. On day- 5 of differentiation, SH-SY $5 Y$ cells were transduced with lentivirus encoding EGFP for neurite detection. Live-cells were imaged two days post-transduction prior to treatment (day-1) and after 8 days of (day-8) treatment on a Leica SP8 confocal microscope using a 10X objective to detect neurites. Differentiated SH-SY5Y cells (100 $\mu \mathrm{L} /$ well) were treated with $5 \mu \mathrm{M}$ of $\mathrm{A} \beta(\mathrm{M} 1-42)$ incubated with or without a variable concentration of $4 \mathrm{~F}(5,10$ and $50 \mu \mathrm{M})$. The effect of $4 \mathrm{~F}$ peptide on undifferentiated SH-SY5Y cells was also measured at 5, 10 and $50 \mu \mathrm{M}$. MTT assay was performed on day-8 to measure the cell-viability following the manufacturer protocol for both differentiated and undifferentiated SH-SY5Y cells.

\section{MD simulations}

All-atom and coarse-grained MD simulations were carried using GROMACS 5.0.7 ${ }^{51}$ running parallel in SGI UV 3000 at the Institute for Protein Research, Osaka University, Japan. The 3D model of $4 \mathrm{~F}$ peptide was built using an ab-initio modeling as described elsewhere ${ }^{28}$. The NMR structure of 
$\mathrm{A} 342$ (PDB ID: 1Z0Q) in aqueous solution was used as an initial model structure for MD simulation using charmm36 force-field ${ }^{52}$. The MD systems were designed by placing two molecules of $A \beta 42$ with 2 molecules of $4 \mathrm{~F}$ peptide separated by a minimum distance of $0.5 \mathrm{~nm}$ in a box size of $9 \mathrm{~nm} \times 9 \mathrm{~nm} \times$ $9 \mathrm{~nm}$. The simulation parameters were adopted from our previous studies. ${ }^{28,36,53}$ Briefly, all MD systems were neutralized and energy minimized using steepest-descent method followed by a short NVT and NPT equilibration MD. The equilibrated systems were next allowed for unrestrained MD simulation for a time-scale of $0.5 \mu$ s at $310.15 \mathrm{~K}$. Coarse-grained MD simulations were carried out by randomly placing 10 Aß42 molecules with or without 10 4F molecules using martini_v2.2P force field in a box size of 18 $\mathrm{nm} \times 18 \mathrm{~nm} \times 18 \mathrm{~nm} . \mathrm{MD}$ trajectories were analyzed using Gromacs tools and graphical interpretations were done using VMD and Chimera. The GMXAPBS tool ${ }^{54,55}$ was used to calculate the binding free energy from $500 \mathrm{MD}$ snapshots retrieved at equal time interval from last 100 ns of $0.5 \mu \mathrm{s}$ MD simulation. A detailed procedure of GMXAPBS calculation followed in this study is provided elsewhere. ${ }^{55}$

\section{Acknowledgements}

This study was supported by funds from NIH (AG048934 to A.R.) and research in Y.W lab is supported by NIH grants (GM130331 and AG062225 to Y.W.). A part of this work (computational simulations) was performed under the International Collaborative Research Program of Institute for Protein Research, Osaka University, ICR-18-02.

\section{References}

1 R. A. Moore, L. M. Taubner and S. A. Priola, Curr. Opin. Struct. Biol., 2009, 19, 14-22.

2 G. M. Ashraf, N. H. Greig, T. A. Khan, I. Hassan, S. Tabrez, S. Shakil, I. A. Sheikh, S. K. Zaidi, M. Akram, N. R. Jabir, C. K. Firoz, A. Naeem, I. M. Alhazza, G. A. Damanhouri and M. A. Kamal, CNS Neurol. Disord. Drug Targets, 2014, 13, 1280-93.

3 P. Sweeney, H. Park, M. Baumann, J. Dunlop, J. Frydman, R. Kopito, A. McCampbell, G. Leblanc, A. Venkateswaran, A. Nurmi and R. Hodgson, Transl. Neurodegener., 2017, 6, 6.

$4 \quad$ I. Benilova, E. Karran and B. De Strooper, Nat. Neurosci., 2012, 15, 349-357.

5 T. J. Esparza, H. Zhao, J. R. Cirrito, N. J. Cairns, R. J. Bateman, D. M. Holtzman and D. L. Brody, Ann. Neurol., 2013, 73, 104-119.

6 S. J. C. Lee, E. Nam, H. J. Lee, M. G. Savelieff and M. H. Lim, Chem. Soc. Rev., 2017, 46, 310323.

7 L. Liao, D. Cheng, J. Wang, D. M. Duong, T. G. Losik, M. Gearing, H. D. Rees, J. J. Lah, A. I. Levey and J. Peng, J. Biol. Chem., 2004, 279, 37061-37068.

8 A. Mouchard, M. C. Boutonnet, C. Mazzocco, N. Biendon and N. Macrez, Sci. Rep., 2019, 9, 3989.

9 Y. Namba, M. Tomonaga, H. Kawasaki, E. Otomo and K. Ikeda, Brain Res., 1991, 541, 163-166. 
P. L. Richey, S. L. Siedlak, M. A. Smith and G. Perry, Biochem. Biophys. Res. Commun., 1995, 208, 657-663.

T. Bilousova, M. Melnik, E. Miyoshi, B. L. Gonzalez, W. W. Poon, H. V. Vinters, C. A. Miller, M. M. Corrada, C. Kawas, A. Hatami, R. Albay, C. Glabe and K. H. Gylys, Am. J. Pathol., 2019, pii: S0002-9440(18)30596-0.

12 A. Kline, Alzheimer's Res. Ther., 2012, 4.

13 P. B. Verghese, J. M. Castellano, K. Garai, Y. Wang, H. Jiang, A. Shah, G. Bu, C. Frieden and D. M. Holtzman, Proc. Natl. Acad. Sci., 2013, 110, E1807-E1816.

14 S. Ghosh, T. B. Sil, S. Dolai and K. Garai, 2019, 1-17.

15 A. C. Paula-Lima, M. A. Tricerri, J. Brito-Moreira, T. R. Bomfim, F. F. Oliveira, M. H. Magdesian, L. T. Grinberg, R. Panizzutti and S. T. Ferreira, Int. J. Biochem. Cell Biol., 2009, 41, 1361-1370. J. Camacho, T. Moliné, A. Bonaterra-Pastra, S. Ramón y Cajal, E. Martínez-Sáez and M. Hernández-Guillamon, Front. Neurol., 2019, 10, 187. T. Oda, P. Wals, H. H. Osterburg, S. A. Johnson, G. M. Pasinetti, T. E. Morgan, I. Rozovsky, W. B. Stine, S. W. Snyder, T. F. Holzman, G. A. Krafft and C. E. Finch, Exp. Neurol., 1995, 136, 22-31. A. R. Nelson, A. P. Sagare and B. V. Zlokovic, Proc. Natl. Acad. Sci., 2017, 114, 8681-8682. A. M. Wojtas, S. S. Kang, B. M. Olley, M. Gatherer, M. Shinohara, P. A. Lozano, C.-C. Liu, A. Kurti, K. E. Baker, D. W. Dickson, M. Yue, L. Petrucelli, G. Bu, R. O. Carare and J. D. Fryer, Proc. Natl. Acad. Sci., 2017, 114, E6962-E6971. A. J. Doig and P. Derreumaux, Curr. Opin. Struct. Biol., 2015, 30, 50-56. F. Belluti, A. Rampa, S. Gobbi and A. Bisi, Expert Opin. Ther. Pat., 2013, 23, 581-596. S. A. Kotler, P. Walsh, J. R. Brender and A. Ramamoorthy, Chem. Soc. Rev., 2014, 43, 66926700.

M. M. M. Wilhelmus, R. M. W. De Waal and M. M. Verbeek, Mol. Neurobiol., 2007, 35, 203-216. A. C. Kim, S. Lim and Y. K. Kim, Int. J. Mol. Sci., 2018, 19. R. J. Baranello, K. L. Bharani, V. Padmaraju, N. Chopra, D. K. Lahiri, N. H. Greig, M. A. Pappolla and K. Sambamurti, Curr. Alzheimer Res., 2015, 12, 32-46. W. Wang and X. Zhu, J. Neurochem., 2018, 147, 580-583. D. Sawmiller, A. Habib, H. Hou, T. Mori, A. Fan, J. Tian, J. Zeng, B. Giunta, P. R. Sanberg, M. P. Mattson and J. Tan, Biol. Psychiatry, 2019, 86, 208-220.

28 B. R. Sahoo, T. Genjo, S. J. Cox, A. K. Stoddard, G. M. Anantharamaiah, C. Fierke and A. Ramamoorthy, J. Mol. Biol., 2018, 430, 4230-4244. C. R. White, G. Datta, L. Wilson, M. N. Palgunachari and G. M. Anantharamaiah, Chem. Phys. Lipids, 2019, 219, 28-35. L. T. Bloedon, R. Dunbar, D. Duffy, P. Pinell-Salles, R. Norris, B. J. DeGroot, R. Movva, M. Navab, A. M. Fogelman and D. J. Rader, J. Lipid Res., 2008, 49, 1344-1352. G. Farias-Eisner, G. M. Anantharamaiah, B. J. Van Lenten, M. Navab, A. M. Fogelman, S. T. Reddy and R. Farias-Eisner, Proc. Natl. Acad. Sci., 2010, 107, 19997-20002. C. Nerelius, A. Sandegren, H. Sargsyan, R. Raunak, H. Leijonmarck, U. Chatterjee, A. Fisahn, S. Imarisio, D. A. Lomas, D. C. Crowther, R. Stromberg and J. Johansson, Proc. Natl. Acad. Sci., 2009, 106, 9191-9196.

34 H. Levine III, Amyloid, 2007, 14, 185-197.

F. E. Cohen and J. W. Kelly, Nature, 2003, 426, 905-909.

B. R. Sahoo, T. Genjo, T. W. Nakayama, A. K. Stoddard, T. Ando, K. Yasuhara, C. A. Fierke and A. Ramamoorthy, Chem. Sci., 2019, 10, 3976-3986.

37 R. Limbocker, S. Chia, F. S. Ruggeri, M. Perni, R. Cascella, G. T. Heller, G. Meisl, B. Mannini, J. Habchi, T. C. T. Michaels, P. K. Challa, M. Ahn, S. T. Casford, N. Fernando, C. K. Xu, N. D. Kloss, S. I. A. Cohen, J. R. Kumita, C. Cecchi, M. Zasloff, S. Linse, T. P. J. Knowles, F. Chiti, M. Vendruscolo and C. M. Dobson, Nat. Commun., 2019, 10, 225.

38 B. R. Sahoo, T. Genjo, M. Bekier, S. J. Cox, A. K. Stoddard, M. Ivanova, K. Yasuhara, C. A. Fierke, Y. Wang and A. Ramamoorthy, Chem. Commun. (Camb)., 2018, 54, 12883-12886.

39 T. L.M., B. T., J. L., R. S.K., Y. K.L., Y. C., P. W.W., C. L.B., M. C.A., V. H.V., V. E. L.J., F. D.W., E. S., B. G., G. K.H. and L. M.J., J. Biol. Chem., 2013, 288, 5914-5926.

40 K. Garai, P. B. Verghese, B. Baban, D. M. Holtzman and C. Frieden, Biochemistry, 2014, 53, 
41 G. S. Getz and C. A. Reardon, J. Inflamm. Res., 2011, 4, 83-92.

42 M. Serra-Batiste, M. Ninot-Pedrosa, M. Bayoumi, M. Gairí, G. Maglia and N. Carulla, Proc. Natl. Acad. Sci., 2016, 113, 10866-10871.

43 C. Dammers, L. Gremer, K. Reiß, A. N. Klein, P. Neudecker, R. Hartmann, N. Sun, H. U. Demuth, M. Schwarten and D. Willbold, PLoS One, 2015, 10, e0143647.

44 J. Roche, Y. Shen, J. H. Lee, J. Ying and A. Bax, Biochemistry, 2016, 55, 762-775.

45 T. Asakura, K. Taoka, M. Demura and M. P. Williamson, J. Biomol. NMR, 1995, 6, 227-236.

46 T. Liu, G. Perry, H. W. Chan, G. Verdile, R. N. Martins, M. A. Smith and C. S. Atwood, J. Neurochem., 2004, 88, 554-563.

47 R. Rönicke, A. Klemm, J. Meinhardt, U. H. Schröder, M. Fändrich and K. G. Reymann, PLoS One, 2008, 9, e3236.

48 S. Yoo, S. Zhang, A. G. Kreutzer and J. S. Nowick, Biochemistry, 2018, 57, 3861-3866.

49 G. Datta, M. Chaddha, S. Hama, M. Navab, A. M. Fogelman, D. W. Garber, V. K. Mishra, R. M. Epand, R. F. Epand, S. Lund-Katz, M. C. Phillips, J. P. Segrest and G. M. Anantharamaiah, J. Lipid Res., 2001, 42, 1096-104.

50 P. Schmieder, .

51 D. Van Der Spoel, E. Lindahl, B. Hess, G. Groenhof, A. E. Mark and H. J. C. Berendsen, J. Comput. Chem., 2005, 26, 1701-1718.

52 J. Huang and A. D. Mackerell, J. Comput. Chem., 2013, 34, 2135-2145.

53 B. R. Sahoo, J. Maharana, G. K. Bhoi, S. K. Lenka, M. C. Patra, M. R. Dikhit, P. K. Dubey, S. K. Pradhan and B. K. Behera, Mol. BioSyst., 2014, 10, 1104-1116.

54 D. Spiliotopoulos, A. Spitaleri and G. Musco, PLoS One, 2012, 7, e46902.

55 B. R. Sahoo, J. Maharana, M. C. Patra, G. K. Bhoi, S. K. Lenka, P. K. Dubey, S. Goyal, B. Dehury and S. K. Pradhan, Colloids Surfaces B Biointerfaces, 2014, 121, 307-318. 